\title{
Corrigendum: Prolyl 3-hydroxylase 1 deficiency causes a recessive meta- bolic bone disorder resembling lethal/severe osteogenesis imperfecta
}

Wayne A Cabral, Weizhong Chang, Aileen M Barnes, MaryAnn Weis, Melissa A Scott, Sergey Leikin, Elena Makareeva, Natalia V Kuznetsova, Kenneth N Rosenbaum, Cynthia J Tifft, Dorothy I Bulas, Chahira Kozma, Peter A Smith, David R Eyre \& Joan C Marini Nat. Genet. 39, 359-365 (2007); published online 4 February 2007; corrected after print 26 June 2008

In the version of this article initially published, the nucleotide positions of the mutations in the LEPRE1 cDNA and genomic DNA sequence in Table 1, Supplementary Table 1 and Supplementary Figure 1 were incorrectly numbered relative to the first nucleotide of exon 1 rather than the first nucleotide of the LEPRE1 start codon. These errors have been corrected in the HTML and PDF versions of the article.

\section{Corrigendum: Hypomorphic mutations in syndromic encephalocele genes} are associated with Bardet-Biedl syndrome

Carmen C Leitch, Norann A Zaghloul, Erica E Davis, Corinne Stoetzel, Anna Diaz-Font, Suzanne Rix, Majid Al-Fadhel, Richard Alan Lewis, Wafaa Eyaid, Eyal Banin, Helene Dollfus, Philip L Beales, Jose L Badano \& Nicholas Katsanis

Nat. Genet. 40, 443-448 (2008); published online 9 March 2008; corrected after print 26 June 2008

In the version of this article initially published, the name of the seventh author was misspelled. The correct author name is Majid Alfadhel. The error has been corrected in the HTML and PDF versions of the article.

\section{Corrigendum: Mutations in 15-hydroxyprostaglandin dehydrogenase cause} primary hypertrophic osteoarthropathy

Sandeep Uppal, Christine P Diggle, Ian M Carr, Colin W G Fishwick, Mushtaq Ahmed, Gamal H Ibrahim, Philip S Helliwell, Anna LatosBieleńska, Simon E V Phillips, Alexander F Markham, Christopher P Bennett \& David T Bonthron

Nat. Genet. 40, 789-793 (2008); published online 25 May 2008; corrected after print 26 June 2008

In the version of this article initially published, Figure 3a-d and Supplementary Figure 2a-c show 16-OH PGE2, not 15-OH PGE2. The errors have been corrected in the HTML and PDF versions of the article.
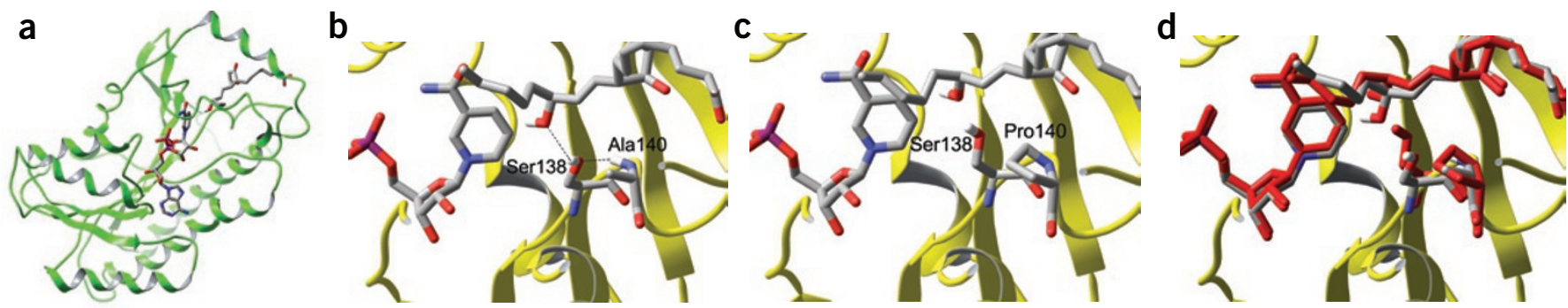